\title{
FORMULATION AND EVALUATION OF FEBUXOSTAT FAST DISSOLVING TABLETS USING ENTADA SCANDENS SEED STARCH AND POLOXAMER-188 AS SUPERDISINTEGRANTS
}

\author{
SANDEEP DOPPALAPUDI*, VIDYADHARA SURYADEVARA, CHIRUDEEP JUJALA
}

Chebrolu Hanumaiah Institute of Pharmaceutical Sciences, Chandramoulipuram, Chowdavaram, Guntur, Andhra Pradesh, India 522019 and Research Scholar, University College of Pharmaceutical Sciences, Acharya Nagarjuna University, Nagarjuna Nagar, Guntur 522510 Email: pharmacydeepu@gmail.com

Received: 04 Jul 2019, Revised and Accepted: 06 Aug 2019

ABSTRACT

Objective: The present study focused on solubility enhancement of the Biopharmaceutical Classification System (BCS) Class-II drug, Febuxostat using various super disintegrants.

Methods: Starches were extracted from Entada scandens seed powder by alkali method i.e., sodium hydroxide at $0.1 \%$, $0.25 \%$ and $0.5 \%$ concentrations and water. Starches were evaluated for various phytochemical and physicochemical tests. Solid dispersions of Febuxostat were prepared by fusion method using poloxamer-188 alone and by mixing poloxamer-188 with Entada scandens seed starch. Various physical parameters were evaluated for these solid dispersions. Tablets were prepared using Febuxostat solid dispersions and varying concentrations of Entada scandens seed starch by direct compression technique. Pre and post-compression parameters were evaluated along with in vitro drug release studies, characterization studies like Fourier Transform Infra-Red spectroscopy (FTIR), Differential Scanning Calorimetry (DSC), Scanning Electron Microscopy (SEM), X-Ray Diffraction (XRD) and stability studies.

Results: Phytochemical tests revealed the presence of starch in all extracts. Starch prepared from 0.5\% sodium hydroxide (ESS4) showed best physicochemical properties. In vitro dissolution studies revealed that solid dispersion F4 containing Febuxostat and poloxamer-188 in 1:3 ratios showed better drug release. Formulation FE5 containing F4 solid dispersion with 12.5\% w/w of ESS4 showed enhanced drug release. FT2 tablets having $12.5 \% \mathrm{w} / \mathrm{w}$ of ESS4 showed better drug release when compared to others. FTIR and DSC studies revealed no major interactions between drug and excipients. XRD studies revealed the nature of formulations. Accelerated stability studies showed that all tablets were stable.

Conclusion: The super disintegrant property of Entada scandens seed starch was evaluated.

Keywords: Febuxostat, Entada scandens, Solid dispersions, Fast dissolving tablets, Poloxamer-188

(c) 2019 The Authors. Published by Innovare Academic Sciences Pvt Ltd. This is an open access article under the CC BY license (http://creativecommons.org/licenses/by/4.0/) DOI: http://dx.doi.org/10.22159/ijap.2019v11i5.34779

\section{INTRODUCTION}

Solubility is an important physicochemical factor which affects drug absorption and therapeutic effectiveness. Nowadays, scientists are focusing on the development of oral dosage forms of poor aqueous solubility drugs through various solubility enhancing approaches [1]. Among these approaches, preparation of solid dispersions is one of the widely used techniques. The term solid dispersion means a group of solid products with at least two different components, i.e., a hydrophilic matrix and a hydrophobic drug [2, 3].

Though drug administration can be made in various routes, the oral route is widely preferred due to its ease. But it is difficult in geriatrics and in children to swallow the drug. To hinder such problems, fast dissolving tablets (FDTs) are developed. These tablets when comes in contact with saliva in the mouth, they rapidly disintegrate and releases drug [4]. Fast dissolving tablets are widely accepted due to patient compliance, fast action, increased bioavailability and quick disintegration [5]. These are prepared by using direct compression technique. Usage of certain super disintegrants like sodium starch glycolate, croscarmellose, polyvinyl pyrrolidine, etc. provides faster tablet disintegration even at low concentrations. They are mixed up with a tablet and some encapsulated formulations which enhance the breakup of tablet and capsules "slugs" into smaller fragments in an aqueous environment which increases the available surface area. This promotes rapid drug release. They promote moisture penetration and dispersion of the tablet matrix $[6,7]$.

Nowadays, natural super disintegrants are preferred over synthetic forms, due to huge availability, economic, non-irritating and non-toxic properties [8]. Several gums and mucilages have super disintegrant property. These are useful in enhancing the water solubility of BCS ClassII drugs. These are drugs with low solubility and high permeability properties. Past studies revealed the applications of components from plants like Ocimum tenuiflorum, mucilages of Plantago ovata, Aloe vera and Hibiscus rosasinesis as super disintegrants [9].
In the present study, an attempt was made to extract starch from of Entada scandens seed powder and to use it as super disintegrant for formulating fast-dissolving tablets. Entada scandens belonging to the family Fabaceae grows in evergreen tropical climates of India, Africa and Australia. Their seeds have a thick and durable seed coat which is brownish in color. It contains a fleshy white cotyledon. These are rich in starch contents [10]. Febuxostat which is an anti-urolithiatic agent is selected as a drug candidate for the present study. It mainly acts by non-competitively inhibiting the enzyme xanthine oxidase. This prevents the conversion of hypoxanthine and xanthine to uric acid, thereby preventing the formation of crystals in kidneys. The bioavailability of Febuxostat is approximately 49\%. More than 99\% of the drug is bound to plasma proteins. It has an approximate elimination half-life of 5-8 $\mathrm{h}$ [11]. Based on pharmacokinetic and pharmacodynamic parameters, Febuxostat is selected as a drug of choice for the present study.

\section{MATERIALS AND METHODS}

\section{Materials}

Febuxostat was a gift sample from Mylan Laboratories Ltd. (Hyderabad, India). Croscarmellose sodium was a gift sample from NATCO Pharma Ltd. (Hyderabad, India). Poloxamer-188 was a gift sample from Pellets Pharma Ltd (Hyderabad, India). Sodium hydroxide, saccharin sodium, magnesium stearate, and talc were procured from S.D Fine Chem. Ltd. (Mumbai, India). Isopropyl alcohol was obtained from High Pure Fine Chem. (Chennai, India). Entada scandens seeds were procured from the local market (Kurnool, Andhra Pradesh, India). The seeds were identified and authenticated by Dr. K. Ammani, Professor and Head, Department of Botany, Acharya Nagarjuna University, Guntur and voucher specimen (17/01) was preserved in Department of Pharmaceutics, Chebrolu Hanumaiah Institute of Pharmaceutical Sciences, Chowdavaram, Guntur, India. 


\section{Extraction of starch from Entada scandens seeds}

Entada scandens seed starch was isolated using aqueous and alkali extraction methods [12]. 5g Entada scandens seed flour was added into $100 \mathrm{ml}$ distilled water, $0.1 \%, 0.25 \%$, and $0.5 \%$ sodium hydroxide solutions separately and soaked ( $6 \mathrm{~h}$ and $8 \mathrm{~h}$ ) at room temperature then stirred constantly. The slurry was filtered through 212 mesh stainless sieve and remaining sediment was washed with distilled water three times. The filtrates were combined and precipitated overnight at $4{ }^{\circ} \mathrm{C}$. The supernatant was discarded and the crude starch was cleaned with distilled water. This step was repeated three times and the starch cake was dried at $40{ }^{\circ} \mathrm{C}$ for $24 \mathrm{~h}$ in oven dryer. The starch was ground with a mortar and pestle. The starches were packed in a plastic bag and kept at room temperature until further use.

\section{Phytochemical tests for Entada scandens seed powder and extracted starches}

The raw Entada scandens seed powder and starches extracted were subjected to various phytochemical tests for identification of carbohydrates, proteins, alkaloids, glycosides, steroids, flavonoids and saponins [13]. The results were indicated in table 1.

\section{Evaluation of physicochemical properties of Entada scandens seed powder and extracted starches}

Various physicochemical properties like gelatinization temperature, $\mathrm{pH}$, viscosity, swelling index, and water absorption index were evaluated using suitable methods [14].

\section{Total microbial load of isolated Entada scandens starch}

The total microbial load is an important parameter which decides the suitability of a substance for use as an excipient in the pharmaceutical dosage form. The starch powders were subjected to dry heat sterilization at $180{ }^{\circ} \mathrm{C}$ for $30 \mathrm{~min}$. Then the starches were inoculated on medium and were incubated for $24 \mathrm{~h}$. Then the colonies were counted using a microbial colony counter. The results were indicated in table 2 .

\section{Preparation of febuxostat solid dispersions by fusion method}

Solid dispersions of Febuxostat were prepared using Poloxamer-188 in different ratios by fusion method. Poloxamer-188 was placed in china dish and heated at $40{ }^{\circ} \mathrm{C}$ until it gets melted and then Febuxostat was added to it. After vigorous stirring in normal temperature, the mixture gets solidified. The solid mass was crushed, pulverized and sieved. The granules obtained were stored in a desiccator for further studies. The results were given in table 3 .

\section{Preparation of febuxostat solid dispersions by fusion method} using Entada scandens seed starch

After performing dissolution studies for Solid dispersions of Febuxostat, the formulation showing best dissolution profile was selected. To that formulation, Entada scandens seed starch (ESS4) was added in increasing concentrations i.e., 2.5, 5.0, 7.5, 10.0, 12.5 and 15.0 by keeping the optimized formulation constant. The optimized formulation was placed in a china dish and heated at $40{ }^{\circ} \mathrm{C}$ until it gets melted and then ESS4 was added to it. After vigorous stirring in normal temperature, the mixture gets solidified. The solid mass was crushed, pulverized and sieved. The granules obtained were stored in a desiccator for further studies. The results were given in table 4 .

\section{Evaluation of physical parameters}

The prepared solid dispersions were evaluated for various physical parameters such as the angle of repose, Carr's index, Hausner's ratio, particle size and drug content [11]. The results were indicated in table 5.

\section{In vitro dissolution studies}

Dissolution studies for all solid dispersions were performed in a calibrated 8 station dissolution test apparatus (LABINDIA DS8000) equipped with paddles employing $900 \mathrm{ml}$ of $0.05 \mathrm{M}$ phosphate buffer $\mathrm{pH} 6.0$ as dissolution medium. The paddles were operated at $50 \mathrm{rpm}$ and the temperature was maintained at $37 \pm 1^{\circ} \mathrm{C}$ throughout the experiment [15]. The samples were withdrawn at 5, 10, 15, 20 and $30 \mathrm{~min}$ and replaced with an equal volume of same dissolution medium to maintain the sink conditions throughout the experiment.
Samples withdrawn were suitably diluted with same dissolution medium and the amount of the drug dissolved was estimated by Lab India double beam U. V spectrophotometer (UV 3000+) at $315 \mathrm{~nm}$. The dissolution profiles were indicated in tables 6 and 7 .

\section{Preparation of febuxostat tablets}

Febuxostat tablets were prepared by direct compression technique. The drug concentration was maintained constant, while the optimized solid dispersion concentration was increased. The raw materials were individually weighed and were then converted into damp mass by using isopropyl alcohol. The damp mass was passed through sieve no 20 to obtain granules and they were kept for drying. The prepared granules were passed through sieve no. 40 . The granules were taken into a plastic bag and lubricated with $1 \%$ talc, magnesium stearate and half of the starch. Then they were compressed as tablets using CLIT 10 station mini-press. To minimize the processing variables all batches of tablets were compressed, under identical conditions. The compositions of various tablet formulations were given in table 8. To minimize the processing variables, all batches of tablets were compressed under identical conditions.

\section{Evaluation of pre-compression parameters}

The prepared granules were evaluated for pre-compression parameters such as the angle of repose, Carr's index and Hausner's ratio [16]. The results were given in table 9.

\section{Evaluation of post-compression parameters}

The compressed tablets were further evaluated for postcompression parameters such as weight uniformity, hardness, friability, wetting time, dispersion test and drug content [17]. The results were given in table 10 .

\section{In vitro dissolution studies of Febuxostat tablets}

Dissolution studies for tablet formulations were performed in a calibrated 8 station dissolution test apparatus (LAB INDIA DS8000) equipped with paddles (USP apparatus II method) employing $900 \mathrm{ml}$ of $0.05 \mathrm{M}$ phosphate buffer $\mathrm{pH} 6.0$ as dissolution medium. The paddles were operated at $50 \mathrm{rpm}$ and the temperature was maintained at $37 \pm 1^{\circ} \mathrm{C}$ throughout the experiment. The samples were withdrawn at $5,10,15$, 20 and 30 min and replaced with an equal volume of same dissolution medium to maintain the constant volume throughout the experiment. Samples were suitably diluted with same dissolution medium and the amount of drug dissolved was estimated by Lab India double beam $\mathrm{U} . \mathrm{V}$ spectrophotometer (UV $3000+$ ) at $315 \mathrm{~nm}$. The dissolution profiles were given in table 11.

\section{Characterization studies}

Based on dissolution studies, the optimized formulations were subjected to FTIR and DSC studies to observe the drug-polymer interactions. X-Ray Diffraction (XRD) studies were performed to detect the nature of formulations. Scanning electron microscopy (SEM) analysis was performed to know surface characteristics. The results were shown in fig. 1, 2, 3 and 4.

\section{Accelerated stability studies}

Accelerated stability studies were carried out on optimized formulations as per International Council for Harmonisation of Technical Requirements for Registration of Pharmaceuticals for Human Use (ICH) guidelines. These studies were carried out to investigate the effect of temperature on the physical properties and drug release of the tablets. The results were given in table 12 .

\section{RESULTS AND DISCUSSION}

\section{Extraction of starch from Entada scandens seeds}

The starches extracted from Entada scandens seed powder were crisp, slightly granular, free-flowing and stable in nature.

\section{Phytochemical screening of Entada scandens seed flour and starch extracts}

The raw Entada scandens seed powder and starches extracted were screened for the presence of various phytochemical constituents. The results were indicated in table 1. 
Table 1: Phytochemical screening of Entada scandens seed powder and starches

\begin{tabular}{lllll}
\hline Test & ESSP & ESS1 & ESS2 & ESS3 \\
\hline Carbohydrates & + & + & + & + \\
Polysaccharides & + & + & - & + \\
Proteins & + & - & - & - \\
Alkaloids & + & - & - & - \\
Glycosides & - & - & - & - \\
Steroids & + & - & - & - \\
Flavonoids & + & - & - & - \\
Saponins & + & - & - \\
\hline
\end{tabular}

+indicates present; -indicates absent

Physicochemical parameters of Entada scandens seed flour and starch extracts

Physicochemical parameters were evaluated for all the starches. The results were indicated in table 2. The starch ESS4 showed high swelling index and water absorption index which made it suitable for selection of solid dispersions and tablets.

\section{Preparation of febuxostat solid dispersions by fusion method}

Solid dispersions of Febuxostat were prepared using poloxamer-188 as a carrier in different ratios by fusion method. The composition was given in table 3 .

\section{Evaluation of physical parameters}

Various physical parameters of Febuxostat solid dispersions were evaluated. The obtained results were indicated in table 5 .

\section{In vitro dissolution studies of febuxostat solid dispersions}

Formulation F4, prepared in 1:3 ratios of Febuxostat and Poloxamer188 showed maximum drug release proving that solid dispersion technique enhances drug release as suggested by the earlier studies $[18,19]$. The dissolution profiles of Febuxostat solid dispersions were given in table 6.

Table 2: Physico-chemical properties of Entada scandens seed powder and starches

\begin{tabular}{lllll}
\hline Properties & ESSP & ESS1 & ESS2 & ESS3 \\
\hline Gelatinization temperature & $218-226^{\circ} \mathrm{C}$ & $220-229^{\circ} \mathrm{C}$ & $222-226^{\circ} \mathrm{C}$ & $224-227^{\circ} \mathrm{C}$ \\
pH & 6.34 & 6.51 & 6.67 & 6.80 \\
Viscosity (in cps) & 1.845 & 2.152 & 2.210 & 2.421 \\
Swelling index & 68 & 72 & 79 & 8.99 \\
Water Absorption Index & Less & More & More & 2.508 \\
Total Microbial Load & Absent & Absent & Absent & More \\
\hline
\end{tabular}

Table 3: Composition of febuxostat solid dispersions prepared by fusion method

\begin{tabular}{ll}
\hline Formulation & Drug: polymer (Febuxostat*: Poloxamer-188) \\
\hline F1 & $1: 0.5$ \\
F2 & $1: 1.0$ \\
F3 & $1: 2.0$ \\
F4 & $1: 3.0$ \\
F5 & $1: 4.0$ \\
F6 & $1: 5.0$ \\
\hline
\end{tabular}

*One part is equal to $40 \mathrm{mg}$, similarly, solid dispersions were prepared by fusion method using Entada scandens seed starch (ESS4) as a carrier in different ratios with a constant amount of optimized formulation (F4). The composition was given in table 4.

Table 4: Composition of febuxostat solid dispersions prepared by fusion method using F4 and Entada scandens seed starch (ESS4)

\begin{tabular}{ll}
\hline Formulation & Percentage of ESS4 in the formulation (\%) \\
\hline FE1 & 2.5 \\
FE2 & 5.0 \\
FE3 & 7.5 \\
FE4 & 10.0 \\
FE5 & 12.5 \\
FE6 & 15.0 \\
\hline
\end{tabular}

Table 5: Physical parameters of febuxostat solid dispersions

\begin{tabular}{llllll}
\hline Solid dispersion & Angle of repose $^{\left({ }^{\circ}\right)}$ & Carr's index (\%) & Hausner's ratio & $\begin{array}{l}\text { Average particle } \\
\text { size }(\boldsymbol{\mu m})\end{array}$ & $\begin{array}{l}\text { Drug content (mg) } \\
(\mathbf{m e a n} \pm \text { SEM) }\end{array}$ \\
\hline FP & & 21 & 1.28 & 41 & $37.32 \pm 0.55$ \\
F1 & 35 & 17 & 1.22 & 180 & $34.14 \pm 0.21$ \\
F2 & 26 & 16 & 1.19 & 174 & $36.84 \pm 0.68$ \\
F3 & 25 & 14 & 1.17 & 177 & $37.72 \pm 0.92$ \\
F4 & 23 & 12 & 1.15 & 167 & $39.90 \pm 0.57$ \\
F5 & 21 & 17 & 1.18 & 172 & $36.17 \pm 0.44$ \\
F6 & 22 & 20 & 1.20 & 179 & $35.51 \pm 0.58$ \\
FE1 & 24 & 18 & 1.26 & 175 & $37.79 \pm 0.67$ \\
FE2 & 30 & 15 & 1.24 & 173 & $38.50 \pm 0.35$ \\
FE3 & 27 & 14 & 1.21 & 170 & $37.86 \pm 0.75$ \\
FE4 & 25 & 11 & 1.19 & 168 & $39.12 \pm 0.23$ \\
FE5 & 21 & 16 & 1.24 & 164 & $37.58 \pm 0.81$ \\
\hline
\end{tabular}

*FP indicates Febuxostat pure drug; n=3, SEM: standard error of mean 
Table 6: Drug release profiles of febuxostat solid dispersions prepared by fusion method

\begin{tabular}{lllllll}
\hline \multirow{2}{*}{$\begin{array}{l}\text { Time } \\
\text { (min) }\end{array}$} & Cumulative \% drug released (mean \pm SEM) & & \\
\cline { 2 - 7 } & FP & F1 & F2 & F3 & F4 & \\
\hline 5 & $2.21 \pm 1.01$ & $37.42 \pm 1.09$ & $41.91 \pm 0.55$ & $50.82 \pm 1.08$ & $51.92 \pm 1.84$ & $45.97 \pm 1.14$ \\
10 & $5.27 \pm 0.95$ & $42.27 \pm 1.45$ & $47.28 \pm 0.81$ & $53.55 \pm 1.88$ & $62.50 \pm 1.11$ & $50.51 \pm 0.32$ \\
15 & $11.29 \pm 0.84$ & $47.71 \pm 0.88$ & $52.71 \pm 1.06$ & $59.70 \pm 0.74$ & $69.02 \pm 1.71$ & $58.70 \pm 1.51$ \\
20 & $14.38 \pm 1.15$ & $52.76 \pm 1.14$ & $59.37 \pm 1.15$ & $67.25 \pm 1.38$ & $73.42 \pm 0.81$ & $66.02 \pm 1.66$ \\
30 & $19.56 \pm 1.07$ & $54.43 \pm 1.60$ & $62.44 \pm 1.66$ & $69.31 \pm 0.50$ & $75.80 \pm 0.67$ & $70.80 \pm 2.02$ \\
\hline
\end{tabular}

$n=3$, SEM: standard error of the mean

Whereas formulation FE5, prepared with F4 and 12.5\%w/w of ESS4 showed maximum drug release. The fusion technique used for the formulation of solid dispersions was also proved to be most advantageous as suggested earlier [20]. The dissolution profiles of Febuxostat solid dispersions were given in table 7.

\section{Preparation of febuxostat tablets}

Febuxostat tablets with various concentrations of Entada scandens seed starch (ESS4) and croscarmellose sodium (CCS) were prepared by direct compression technique. Formulations FT1 to FT3 were prepared using 10.0 to $15 \%$ of alkali extracted starch (ESS4). Formulations FT4 to FT6 were prepared using 10.0 to $15 \%$ of CCS. Whereas the formulation FTP doesn't contain only the solid dispersion FE5. The compositions were given in table 8 .

\section{Evaluation of pre-compression parameters}

The pre-compression parameter values obtained for various prepared granules were given in table 9. The angle of repose, Carr's index, and Hausner's ratio values for granules were within the range specified. Thus all the prepared granules were found to be stable and suitable for compression of tablets.

Table 7: Drug release profiles of febuxostat solid dispersions prepared by fusion method using F4 and Entada scandens seed starch

\begin{tabular}{lllllll}
\hline \multirow{2}{*}{$\begin{array}{l}\text { Time } \\
\text { (min) }\end{array}$} & FP & FE1 & FE2 & FE3 & FE4 \\
\hline 5 & $2.21 \pm 1.01$ & $71.24 \pm 1.42$ & $74.94 \pm 0.42$ & $79.81 \pm 1.51$ & $76.54 \pm 1.47$ \\
10 & $5.27 \pm 0.95$ & $84.71 \pm 1.08$ & $86.20 \pm 0.91$ & $89.63 \pm 1.98$ & $90.07 \pm 0.91$ & $81.72 \pm 1.24$ \\
15 & $11.29 \pm 0.84$ & $91.08 \pm 0.91$ & $93.88 \pm 1.65$ & $95.77 \pm 0.69$ & $95.73 \pm 1.67$ & $94.22 \pm 1.78$ \\
20 & $14.38 \pm 1.15$ & $93.11 \pm 1.54$ & $95.37 \pm 1.07$ & $97.61 \pm 1.37$ & $96.25 \pm 1.83$ & $98.67 \pm 1.99$ \\
30 & $19.56 \pm 1.07$ & $94.31 \pm 1.11$ & $96.63 \pm 1.52$ & $98.24 \pm 0.73$ & $97.48 \pm 1.06$ & $99.91 \pm 1.65$ \\
\hline
\end{tabular}

$\mathrm{n}=3$, SEM: standard error of the mean

Table 8: Composition of febuxostat tablets with different polymer concentrations

\begin{tabular}{|c|c|c|c|c|c|c|c|}
\hline \multirow[t]{2}{*}{ Ingredient (mg/tablet) } & \multicolumn{7}{|c|}{ Formulations } \\
\hline & FTP & FT1 & FT2 & FT3 & FT4 & FT5 & FT6 \\
\hline FE5 Solid Dispersion & 180 & 180 & 180 & 180 & 180 & 180 & 180 \\
\hline Spray Dried Lactose & 112.5 & 82.50 & 75.0 & 67.50 & 82.50 & 75.0 & 67.50 \\
\hline ESS4 & ----- & 30.0 & 37.50 & 45.0 & ---- & ----- & ----- \\
\hline CCS & ---- & ---- & ----- & ---- & 30.0 & 37.50 & 45.0 \\
\hline Saccharin Sodium & 5 & 5 & 5 & 5 & 5 & 5 & 5 \\
\hline Isopropyl Alcohol & Q.S & Q.S & Q.S & Q.S & Q.S & Q. S & Q.S \\
\hline Lemon Flavour & Q.S & Q.S & Q.S & Q.S & Q.S & Q.S & Q.S \\
\hline Talc & 1.25 & 1.25 & 1.25 & 1.25 & 1.25 & 1.25 & 1.25 \\
\hline Magnesium Stearate & 1.25 & 1.25 & 1.25 & 1.25 & 1.25 & 1.25 & 1.25 \\
\hline Total Weight & 300 & 300 & 300 & 300 & 300 & 300 & 300 \\
\hline
\end{tabular}

Q. S indicates quantity sufficient

Table 9: Pre-compression parameters of granules prepared for tablet formulations

\begin{tabular}{llll}
\hline Formulation & Angle of repose $\left(^{\circ}\right)$ & Carr's index (\%) & Hausner's ratio \\
\hline FTP & 30 & 19 & 1.20 \\
FT1 & 24 & 14 & 1.15 \\
FT2 & 23 & 12 & 1.13 \\
FT3 & 25 & 13 & 1.14 \\
FT4 & 26 & 15 & 1.16 \\
FT5 & 23 & 12 & 1.13 \\
FT6 & 25 & 14 & 1.15 \\
\hline
\end{tabular}

Evaluation of post-compression characteristics of febuxostat tablets

The direct compression method was found to be suitable for preparation of fast dissolving tablets. All the batches of tablets were compressed under identical conditions to minimize processing variables. They were evaluated for post-compression parameters such as weight uniformity, hardness, friability, wetting time, dispersion test and drug content. The results were given in table 10 . Weight uniformity, hardness and friability loss of tablet formulations were within the specified limits and were found to be stable and suitable for further studies. 
Table 10: Post compression parameters of various febuxostat tablet formulations

\begin{tabular}{|c|c|c|c|c|c|c|}
\hline Formulation & $\begin{array}{l}\text { Weight uniformity } \\
\text { (mg) }\end{array}$ & $\begin{array}{l}\text { Hardness } \\
\left(\mathrm{kg} / \mathrm{cm}^{2}\right)\end{array}$ & $\begin{array}{l}\text { Friability } \\
\text { (\% loss) }\end{array}$ & $\begin{array}{l}\text { Wetting time } \\
\text { (sec) }\end{array}$ & $\begin{array}{l}\text { Dispersion time } \\
\text { (sec) }\end{array}$ & $\begin{array}{l}\text { Drug content } \\
\text { (mg/tablet) (mean } \pm \text { SEM) }\end{array}$ \\
\hline FTP & $297 \pm 1.05$ & $3.3 \pm 0.82$ & 0.3 & 210 & Passed & $36.64 \pm 1.08$ \\
\hline FT1 & $299 \pm 1.42$ & $3.2 \pm 1.48$ & 0.3 & 74 & Passed & $40.71 \pm 0.97$ \\
\hline FT2 & $300 \pm 0.88$ & $3.0 \pm 1.03$ & 0.2 & 60 & Passed & $40.22 \pm 1.56$ \\
\hline FT3 & $298 \pm 1.07$ & $3.2 \pm 0.65$ & 0.4 & 69 & Passed & $38.49 \pm 1.22$ \\
\hline FT4 & $299 \pm 1.43$ & $3.2 \pm 1.27$ & 0.3 & 88 & Passed & $39.90 \pm 1.48$ \\
\hline FT5 & $300 \pm 1.02$ & $3.0 \pm 1.11$ & 0.2 & 64 & Passed & $40.32 \pm 1.73$ \\
\hline FT6 & $300 \pm 1.77$ & $3.3 \pm 1.34$ & 0.3 & 71 & Passed & $38.16 \pm 1.08$ \\
\hline
\end{tabular}

$\mathrm{n}=6$; SEM is the standard error of the mean

\section{In vitro dissolution studies of febuxostat tablets}

Dissolution studies were carried on Febuxostat tablets using U. S. P paddle method (apparatus II) with $0.05 \mathrm{M}$ phosphate buffer $\mathrm{pH} 6.0$ as dissolution medium by maintaining the bath temperature at $37+1{ }^{\circ} \mathrm{C}$ and the paddles were operated at $50 \mathrm{rpm}$. The dissolution profiles of tablets were given in table 11. It was observed that the proportion of starch as super disintegrant has greatly influenced the dissolution parameters of various formulations. Formulation FT2 containing
$12.5 \% \mathrm{w} / \mathrm{w}$ of ESS4 as super disintegrant exhibited closer dissolution profile with that of formulation FT5 prepared by $12.5 \%$ $\mathrm{w} / \mathrm{w}$ of CCS. Several studies have been carried out previously indicating the advantages of super disintegrants in solubility enhancement [21]. Those studies suggest the usage of a mixture of super disintegrants rather than single [22]. Recent works focus on the natural starches application as super disintegrants [23, 24]. They have successfully proved the efficacy of natural starches as pharmaceutical excipients.

Table 11: Dissolution profiles of febuxostat tablets prepared by direct compression method (FT1-FT6)

\begin{tabular}{|c|c|c|c|c|c|c|c|}
\hline \multirow[t]{2}{*}{ Time (min) } & \multicolumn{5}{|c|}{ Cumulative \% drug released (mean \pm SEM) } & \multirow[b]{2}{*}{ FT5 } & \multirow[b]{2}{*}{ FT6 } \\
\hline & FTP & FT1 & FT2 & FT3 & FT4 & & \\
\hline 5 & $36.22 \pm 0.84$ & $88.08 \pm 1.27$ & $89.79 \pm 1.82$ & $86.43 \pm 1.91$ & $86.04 \pm 1.57$ & $88.91 \pm 1.06$ & $86.37 \pm 1.64$ \\
\hline 10 & $39.45 \pm 1.06$ & $94.19 \pm 1.89$ & $97.87 \pm 1.24$ & $92.81 \pm 1.37$ & $92.57 \pm 1.72$ & $95.12 \pm 1.31$ & $92.13 \pm 1.22$ \\
\hline 15 & $44.46 \pm 1.47$ & $98.26 \pm 2.01$ & $99.46 \pm 1.94$ & $96.17 \pm 1.49$ & $96.31 \pm 1.18$ & $97.67 \pm 1.45$ & $93.66 \pm 1.19$ \\
\hline 20 & $57.61 \pm 1.62$ & $98.97 \pm 1.87$ & $99.50 \pm 1.31$ & $97.41 \pm 1.22$ & $97.62 \pm 1.44$ & $98.32 \pm 1.76$ & $94.74 \pm 2.11$ \\
\hline 30 & $65.56 \pm 1.37$ & $99.38 \pm 1.66$ & $99.68 \pm 1.28$ & $98.88 \pm 1.06$ & $97.91 \pm 1.65$ & $99.09 \pm 1.37$ & $95.81 \pm 1.08$ \\
\hline
\end{tabular}

$\mathrm{n}=3$; SEM is the standard error of the mean

\section{Characterization of febuxostat fast dissolving tablets}

\section{FT-IR spectra}

The FT-IR spectral investigations were carried out on pure drug of Febuxostat, ESS4, CCS, poloxamer-188, sold dispersions F4 and FE5, fast dissolving tablets of Febuxostat FT2 and FT5. Febuxostat pure drug exhibited sharp peaks at $2228.03 \mathrm{~cm}^{-1}, 1682.28 \mathrm{~cm}^{-1}$, $1011.49 \mathrm{~cm}^{-1}$ and $767.05 \mathrm{~cm}^{-1}$ indicating the presence of $\mathrm{C}=\mathrm{C}$ stretching, $-\mathrm{C}=\mathrm{O}$ stretching, $-\mathrm{C}=\mathrm{N}$-stretching, $\equiv \mathrm{C}$ - $\mathrm{O}$-stretching and$\mathrm{N}=\mathrm{H}$ wag. Starch extracted from Entada scandens, ESS4 exhibited sharp peaks at $3049.42 \mathrm{~cm}^{-1}, 1645.74 \mathrm{~cm}^{-1}, 1242.69 \mathrm{~cm}^{-1}$ and $1014.79 \mathrm{~cm}^{-1}$ indicating the presence of $\equiv \mathrm{C}-\mathrm{H}$ stretching, $\mathrm{C}=\mathrm{O}$ stretching, $\mathrm{C}-\mathrm{H}$ wag, and $\equiv \mathrm{C}-\mathrm{O}$-stretching. Whereas CCS exhibited sharp peaks at $1409.53 \mathrm{~cm}^{-1}, 1059.82 \mathrm{~cm}^{-1}$ and $897.37 \mathrm{~cm}^{-1}$ indicating the presence of $-\mathrm{C} \equiv \mathrm{N}$ bending, $-\mathrm{C}=\mathrm{N}$-stretching and $\equiv \mathrm{C}-\mathrm{H}$ bending. Poloxamer-188 exhibited sharp peaks at $2237.60 \mathrm{~cm}^{-1}$, $1643.70 \mathrm{~cm}^{-1}, 1407.39 \mathrm{~cm}^{-1}$ and $1281.02 \mathrm{~cm}^{-1}$ indicating the presence of $\mathrm{C}=\mathrm{C}$ stretching, $-\mathrm{C}=\mathrm{O}$ stretching, $-\mathrm{C} \equiv \mathrm{N}$ bending and $\mathrm{C}-\mathrm{H}$ wag. Formulation F4, solid dispersion made with Febuxostat and poloxamer-188 in 1:3 ratio exhibited strong peaks at $2231.37 \mathrm{~cm}^{-1}$, $1679.53 \mathrm{~cm}^{-1}, 1402.12 \mathrm{~cm}^{-1}, 1274.50 \mathrm{~cm}^{-1}, 1011.81 \mathrm{~cm}^{-1}$ and $762.71 \mathrm{~cm}^{-1}$ indicating the presence of $\mathrm{C}=\mathrm{C}$ stretching, $-\mathrm{C}=\mathrm{O}$ stretching, $-\mathrm{C} \equiv \mathrm{N}$ bending, $\mathrm{C}-\mathrm{H}$ wag, $\equiv \mathrm{C}-\mathrm{O}$-stretching and $-\mathrm{N}=\mathrm{H}$ wag. Formulation FE5, solid dispersion made with $\mathrm{F} 4$ and $12.5 \% \mathrm{w} / \mathrm{w}$ ESS4 exhibited strong peaks at $2230.92 \mathrm{~cm}^{-1}, 1609.65 \mathrm{~cm}^{-1}$, $1275.84 \mathrm{~cm}^{-1}$, and $763.49 \mathrm{~cm}^{-1}$ indicating the presence of $\mathrm{C}=\mathrm{C}$ stretching, $-\mathrm{C}=\mathrm{O}$ stretching, $\mathrm{C}-\mathrm{H}$ wag and $-\mathrm{N}=\mathrm{H}$ wag. $\mathrm{FT2}$, an $\mathrm{FDT}$ prepared with Febuxostat, FE5 and $12.5 \% \mathrm{w} / \mathrm{w}$ ESS4 exhibited peaks at $2230.44 \mathrm{~cm}^{-1}, 1656.80 \mathrm{~cm}^{-1}, 949.23 \mathrm{~cm}^{-1}$ and $763.99 \mathrm{~cm}^{-1}$ indicating the presence of $\mathrm{C}=\mathrm{C}$ stretching, $-\mathrm{C}=\mathrm{O}$ stretching, $-\mathrm{O}-\mathrm{H}$ bending and $-\mathrm{N}=\mathrm{H}$ wag. FT5, an FDT prepared with Febuxostat, FE5 and $12.5 \% \mathrm{w} / \mathrm{w}$ CCS exhibited peaks at $1638.13 \mathrm{~cm}^{-1}, 1413.59$ $\mathrm{cm}^{-1}$ and $1059.33 \mathrm{~cm}^{-1}$ indicating the presence of- $\mathrm{C}=0$ stretching,$\mathrm{C} \equiv \mathrm{N}$ bending and- $\mathrm{C} \equiv \mathrm{N}$ stretching. The detailed spectral elucidations were shown in fig. 1.

\section{DSC thermograms}

The DSC thermographic studies were carried out on pure drug of Febuxostat, ESS4, CCS, poloxamer-188, sold dispersions F4 and FE5, fast dissolving tablets of Febuxostat FT2 and FT5. These studies exhibited broad endothermic peaks at $217.42{ }^{\circ} \mathrm{C}, 266.29{ }^{\circ} \mathrm{C}$ and $303.83{ }^{\circ} \mathrm{C}$ for Febuxostat pure drug, a broad endothermic peak at $311.1{ }^{\circ} \mathrm{C}$ for ESS4, a sharp endothermic peak at $59.06{ }^{\circ} \mathrm{C}$ for poloxamer-188, a sharp exothermic peak at $319.1^{\circ} \mathrm{C}$ for CCS, broad endothermic peaks at $60.70{ }^{\circ} \mathrm{C}$ and $307.55^{\circ} \mathrm{C}$ for $\mathrm{F} 4$ solid dispersion, broad endothermic peaks at $58.69^{\circ} \mathrm{C}, 236.64{ }^{\circ} \mathrm{C}$ and $301.53{ }^{\circ} \mathrm{C}$ for FE5 solid dispersion which has ESS4. Broad endothermic peaks were observed at $57.94{ }^{\circ} \mathrm{C}, 222.45{ }^{\circ} \mathrm{C}, 230.25{ }^{\circ} \mathrm{C}$, and $302.66{ }^{\circ} \mathrm{C}$ for formulation FT2, which is an FDT made with Febuxostat and ESS4 along with FE5. A sharp endothermic peak at $270.12{ }^{\circ} \mathrm{C}$, a broad endothermic peak at $312.82{ }^{\circ} \mathrm{C}$ and a sharp exothermic peak at $376.55^{\circ} \mathrm{C}$ were observed for formulation FT5, which is an FDT made with Febuxostat and CCS along with FE5. It was observed that there is a slight shift in temperature for drug and CCS. The detailed thermographs were shown in fig. 2.

\section{SEM studies}

Scanning electron microscopy images were taken for Febuxostat pure drug, ESS4, CCS, poloxamer-188, a blend of Febuxostat with poloxamer-188, Febuxostat with poloxamer-188 and ESS4 and Febuxostat with poloxamer-188 and CCS. Febuxostat pure drug exhibited crystalline form. The ESS4 starch exhibited a free-flowing spherical low dense form of starch grains without any mucilage/resinous coverage. Poloxamer-188 exhibited clear spherical granules. CCS exhibited blunt tubular-shaped crystals. The SEM image of Febuxostat with ESS4 clearly exhibited uniform dispersion of drug with spherical globular starch grains. The SEM image of Febuxostat with ESS4 and poloxamer-188 showed complete dispersion of drug with both the polymers. The SEM image of Febuxostat with CCS showed uniform dispersion of drug with blunt tubular crystals of CCS. The detailed SEM images were shown in fig. 3. 


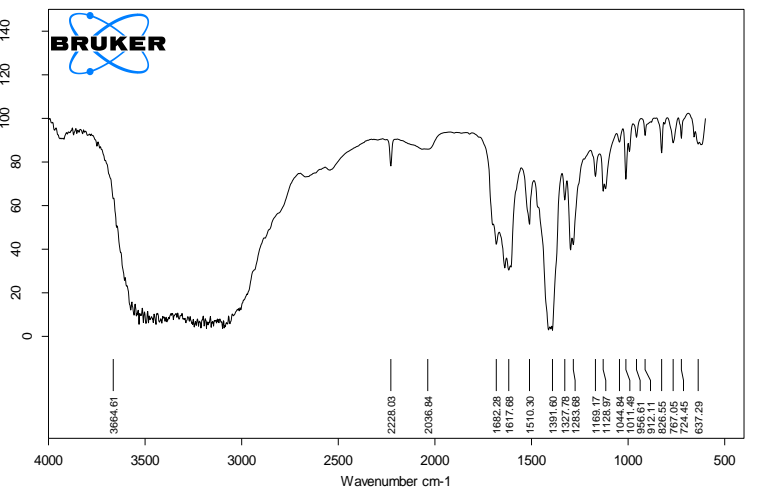

(A)

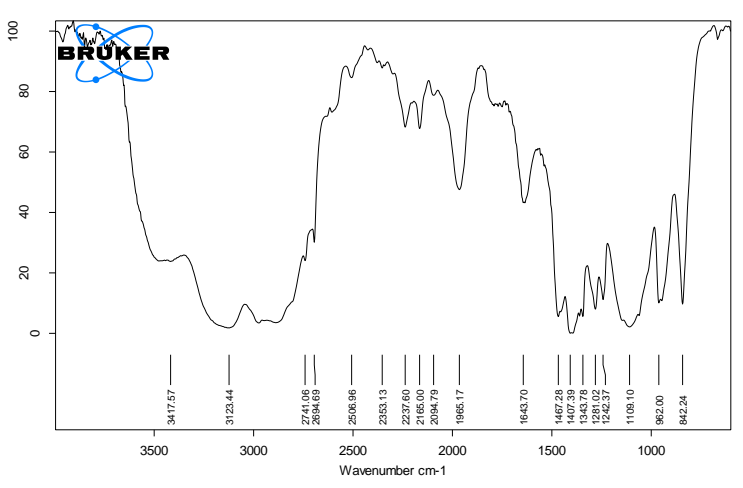

(C)

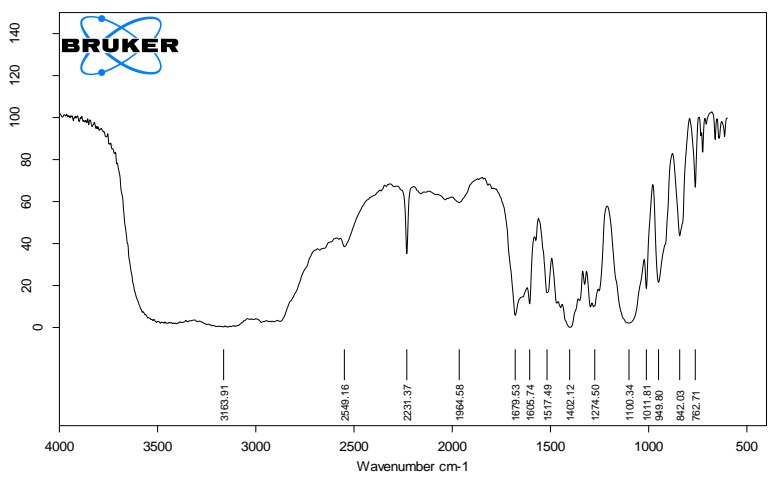

(E)

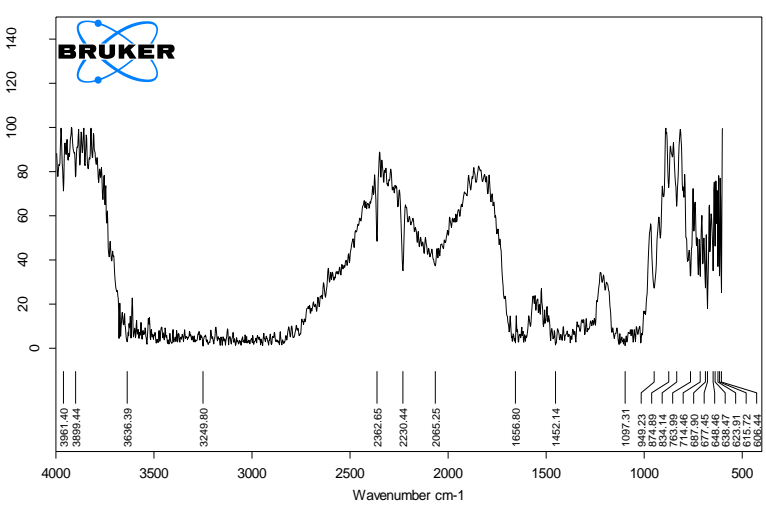

(G)

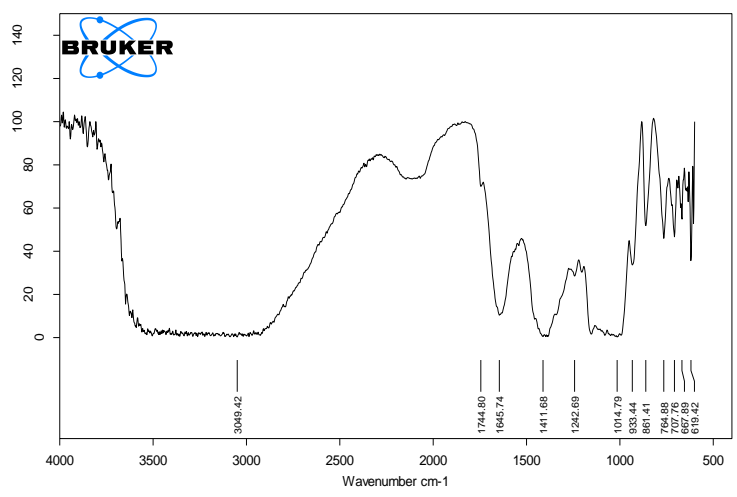

(B)

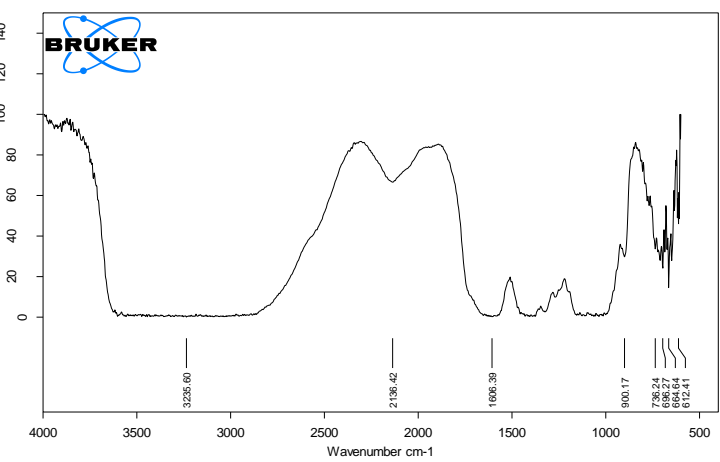

(D)

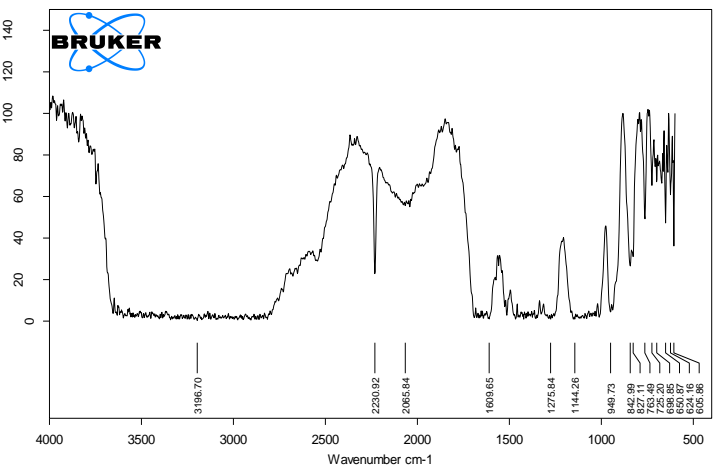

(F)

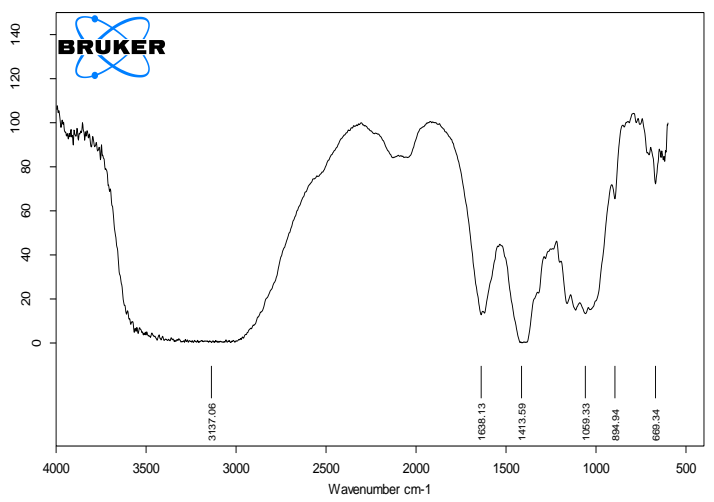

(H)

Fig. 1: FT-IR spectra: (A) Febuxostat pure drug (B) ESS4 (C) Poloxamer-188 (D) CCS, (E) F4 (F) FE5 (G) FT2 (H) FT5, ESS4-Entada scandens seed starch extracted by $0.5 \%$ sodium hydroxide; CCS-Croscarmellose sodium; F4-Febuxostat and poloxamer-188 solid dispersion in 1:3 ratio; FE5-F4 solid dispersion with $12.5 \%$ w/w of ESS4; FT2-Febuxostat FDT with 12.5\% w/w of ESS4; FT5-Febuxostat FDT with 12.5\% $\mathbf{w} / \mathbf{w}$ of CCS 


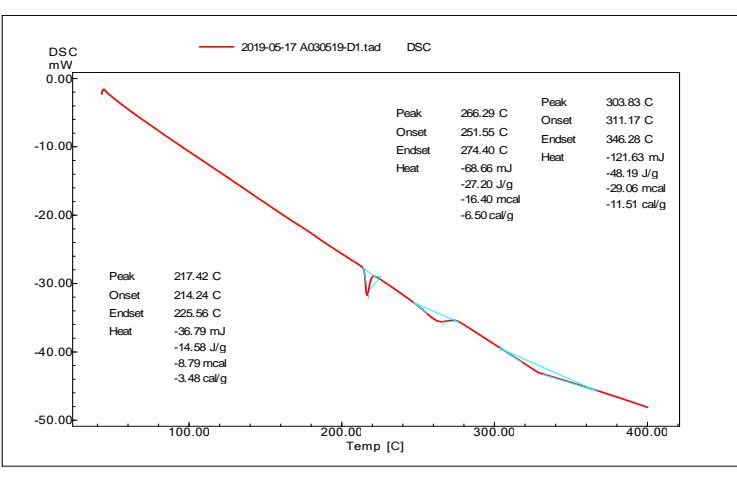

(A)

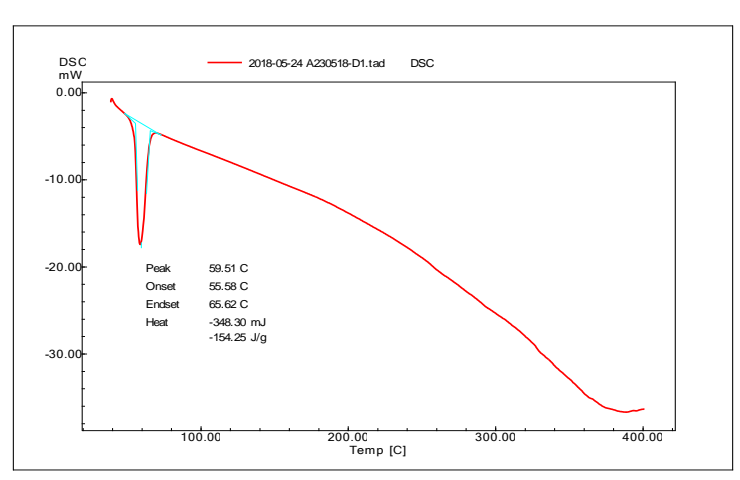

(C)

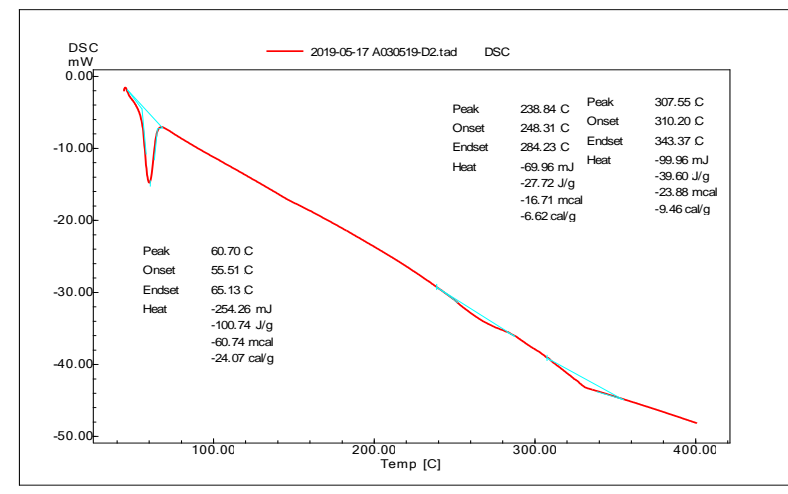

(E)

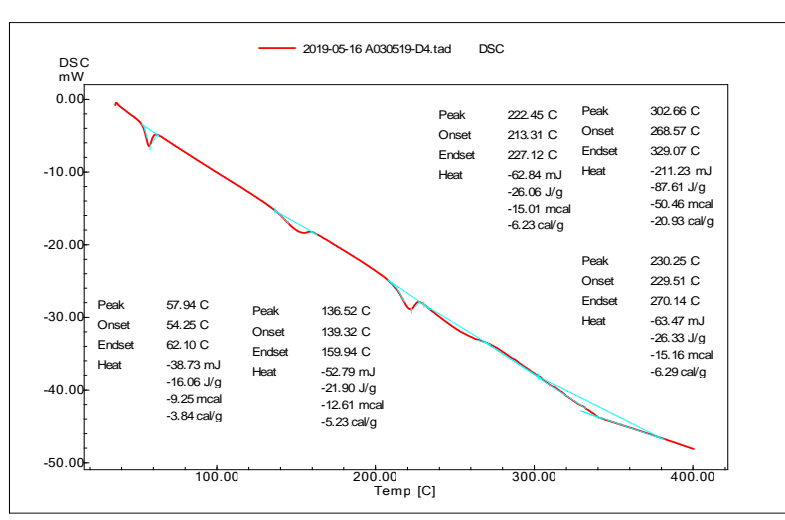

(G)

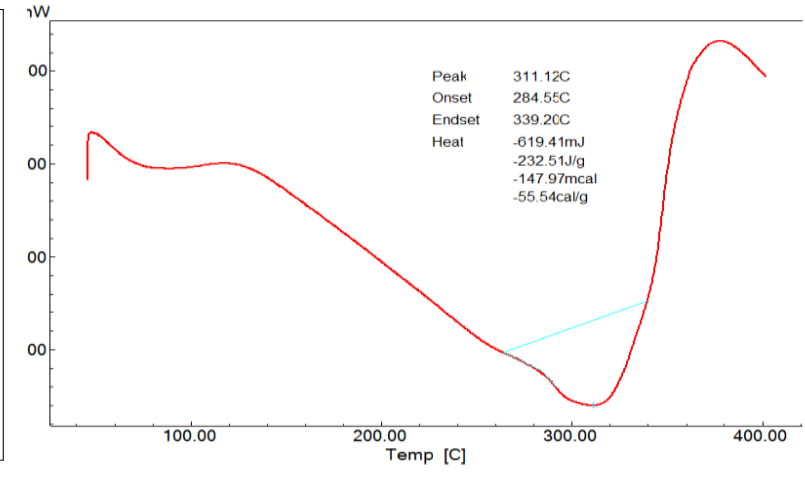

(B)

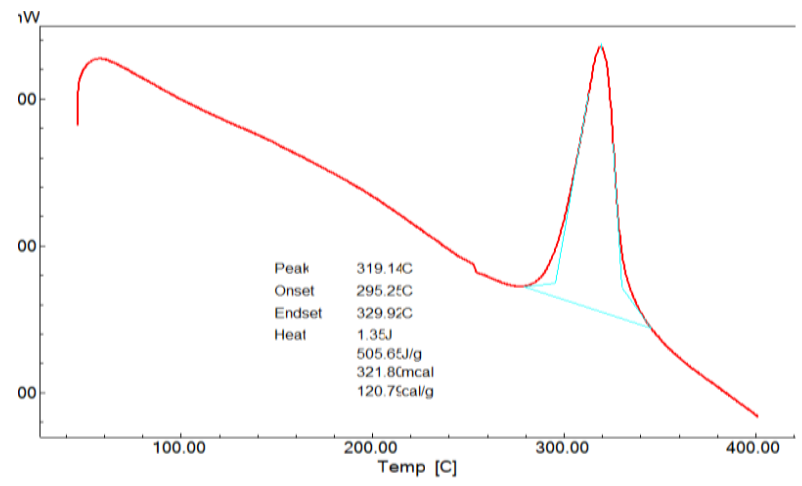

(D)

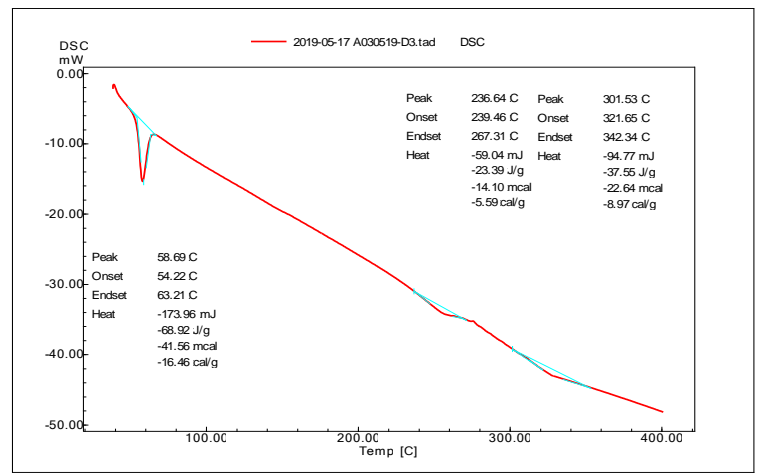

(F)

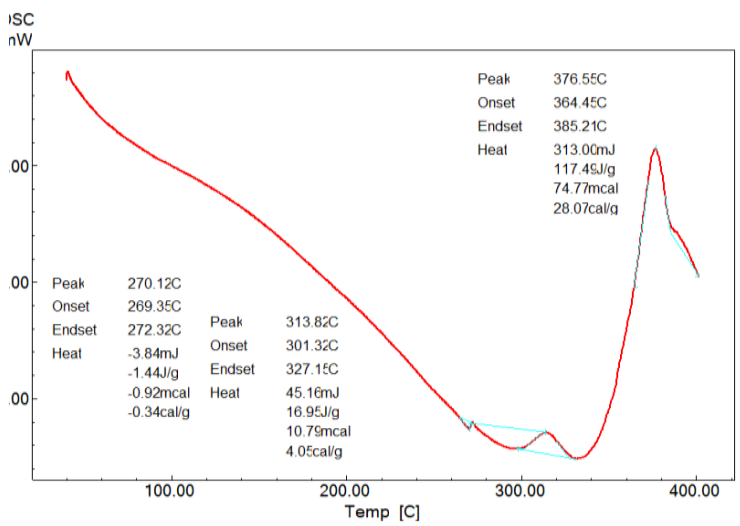

(H)

Fig. 2: DSC thermograms: (A) Febuxostat pure drug (B) ESS4 (C) Poloxamer-188, (D) CCS (E) F4 (F) FE5 (G) FT2 (H) FT5, ESS4-Entada scandens seed starch extracted by $0.5 \%$ sodium hydroxide; CCS-Croscarmellose sodium; F4-Febuxostat and poloxamer-188 solid dispersion in 1:3 ratio; FE5-F4 solid dispersion with 12.5\% w/w of ESS4; FT2-Febuxostat FDT with 12.5\% w/w of ESS4; FT5-Febuxostat FDT with $12.5 \% \mathrm{w} / \mathrm{w}$ of CCS 


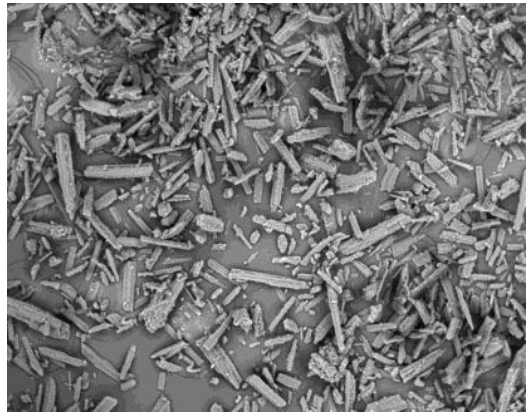

(A)

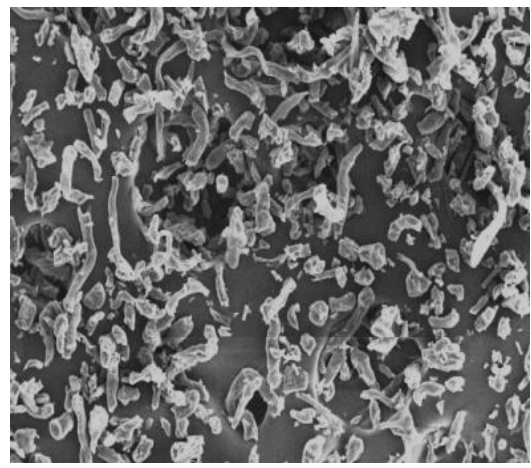

(D)

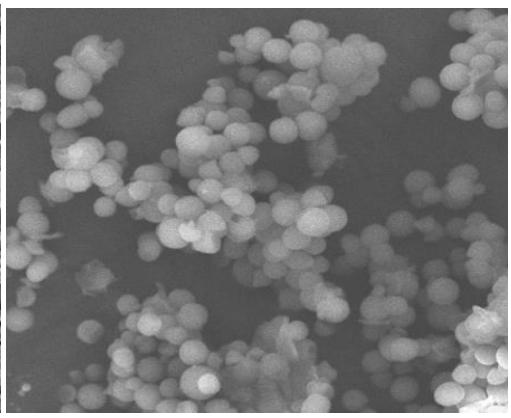

(B)

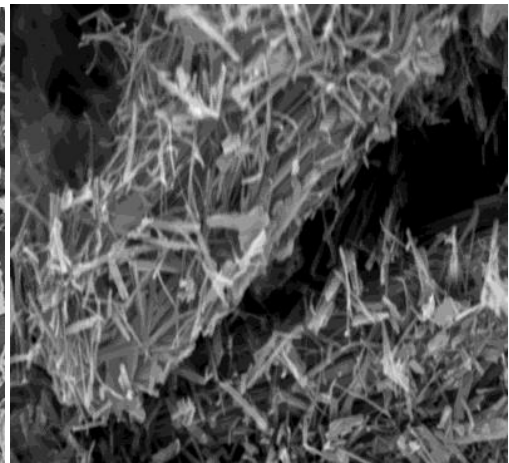

(E)

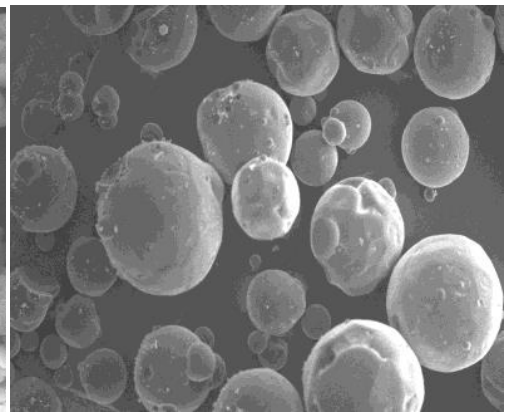

(C)

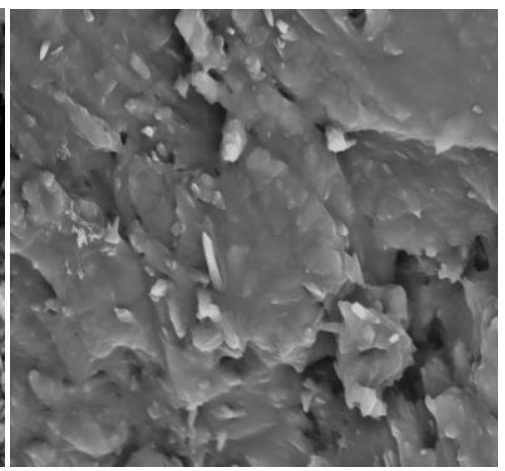

(F)

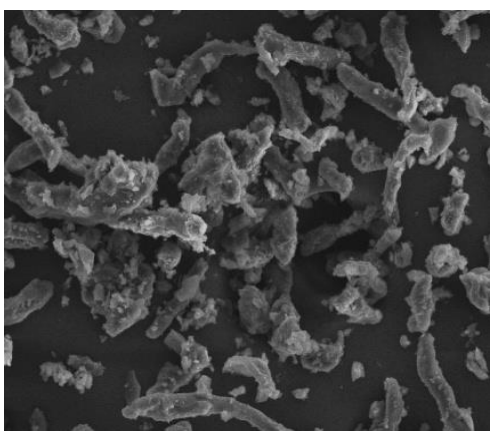

(G)

Fig. 3: SEM images: (A) Febuxostat pure drug (B) ESS4 (C) Poloxamer-188, (D) CCS (E) A blend of Febuxostat with poloxamer-188 (F) A blend of Febuxostat with poloxamer-188 and ESS4 (G) A blend of Febuxostat with CCS, ESS4-Entada scandens seed starch extracted by $0.5 \%$ sodium hydroxide; CCS-Croscarmellose sodium

\section{X-ray diffractograms}

XRD diffraction studies were carried out for pure drug of Febuxostat, ESS4, CCS, poloxamer-188, Sold dispersions F4 and FE5, fast dissolving tablets of Febuxostat FT2 and FT5. The X-ray diffractogram of Febuxostat showed sharp and intense peaks at diffraction angles $(2 \theta)$ of $12.082,25.360^{\circ}$ and $26.220^{\circ}$ indicating a typical crystalline pattern. Whereas ESS4 showed intense peaks at diffraction angles $(2 \theta)$ of $17.730^{\circ}, 24.251^{\circ}$, and $33.531^{\circ}$. Poloxamer188 showed sharp peaks at diffraction angles $(2 \theta)$ of $18.214^{\circ}$, $23.341^{\circ}$ and $27.127^{\circ}$ CCS showed sharp and intense peaks at diffraction angles $(2 \theta)$ of $21.770^{\circ}, 22.741^{\circ}, 25.292^{\circ}$ and $30.210^{\circ}$ indicating crystalline nature. Formulation, F4 which is a solid dispersion of Febuxostat and poloxamer-188 showed sharp and intense peaks at diffraction angles $(2 \theta)$ of $13.102^{\circ}, 19.317^{\circ}$, and $23.445^{\circ}$ indicating the disappearance of some of the crystalline peaks of drug and poloxamer-188. Formulation, FE5 which is a solid dispersion of Febuxostat and poloxamer-188 with ESS4 showed

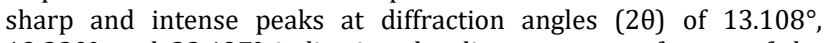
$19.330^{\circ}$, and $23.497^{\circ}$ indicating the disappearance of some of the crystalline peaks of the drug, poloxamer-188, and ESS4. This shows the formation of a new solid phase. Formulation, FT2 which is an FDT of Febuxostat and ESS4 showed sharp and intense peaks at diffraction angles $(2 \theta)$ of $18.240^{\circ}, 19.800^{\circ}$, and $21.054^{\circ}$ indicating the disappearance of most of the crystalline peaks of drug and ESS4. Formulation, FT5 which is an FDT of Febuxostat and CCS showed sharp and intense peaks at diffraction angles $(2 \theta)$ of $13.024^{\circ}, 22.547$ $\circ$, and $26.334^{\circ}$ indicating the disappearance of most of the crystalline peaks of drug and CCS. This suggests the formation of a new solid phase with a lower degree of crystallinity due to complexation. The detailed diffractograms were shown in fig. 4.

\section{Accelerated stability studies of Febuxostat fast dissolving tablets}

The fast-dissolving tablets FT2 and FT5 containing Febuxostat with FE5 solid dispersion mixed with ESS4 and CCS in $12.5 \% \mathrm{w} / \mathrm{w}$ respectively showed well in vitro dissolution and so was subjected to accelerated stability studies. The results were indicated in table 12 .

The results showed that there were no visible and physical changes observed in the FDTs after storage. Weight uniformity, hardness, friability, wetting time, dispersion test and drug content were found to be uniform before and after storage at different conditions. It was also observed that there was no significant change in drug release from the FDTs. Thus the drug release characteristics of FDTs designed were found to be quite stable. 


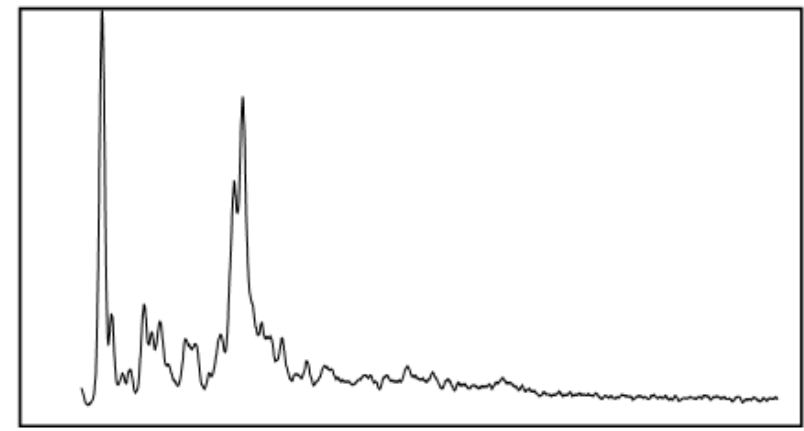

A
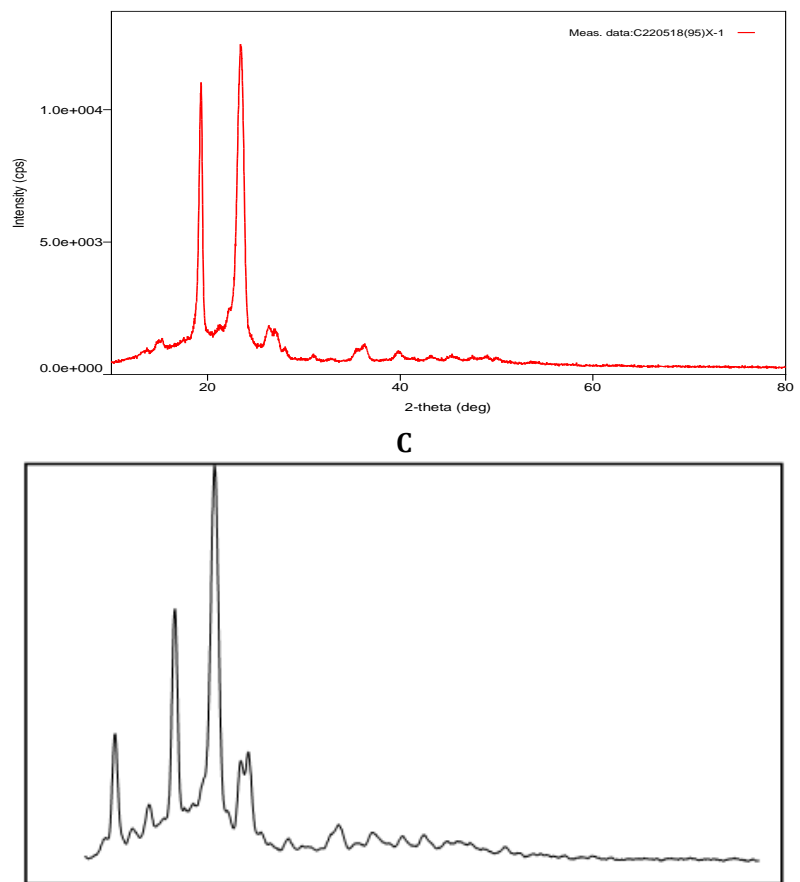

$\mathbf{E}$

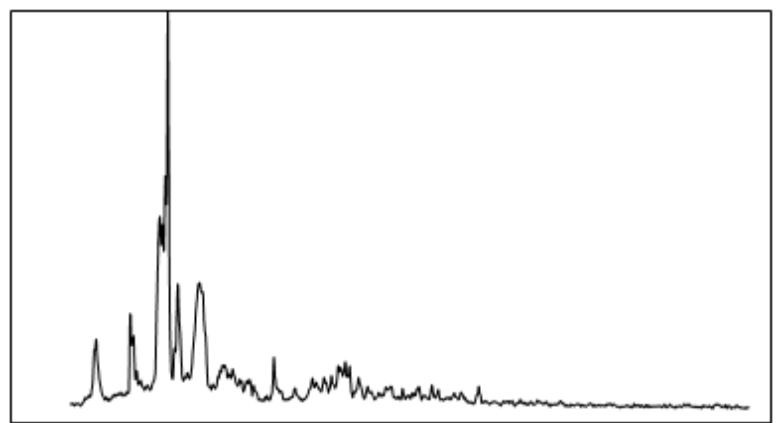

G
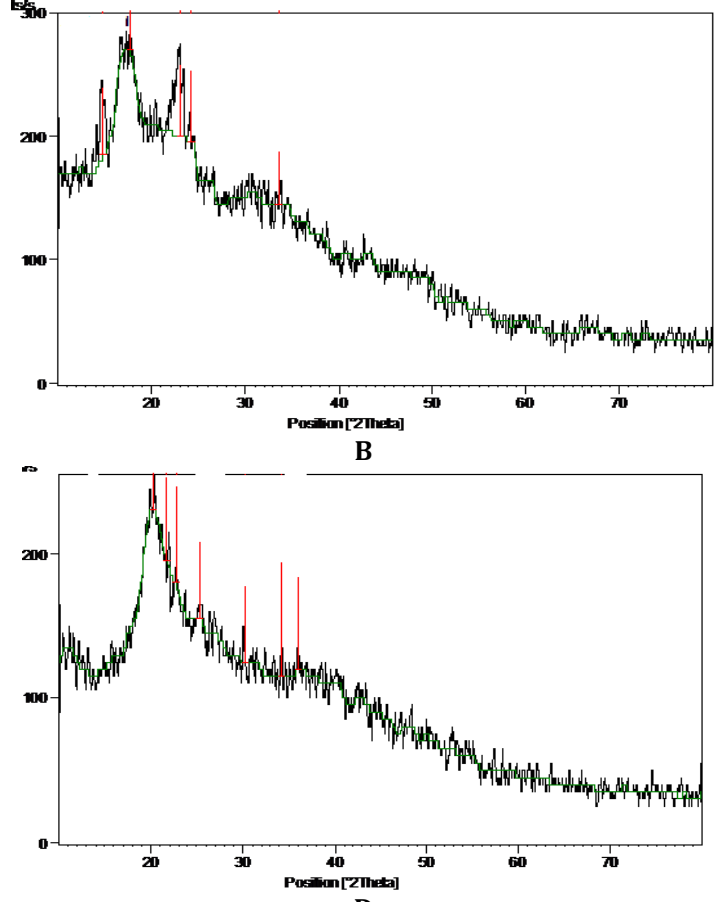

D

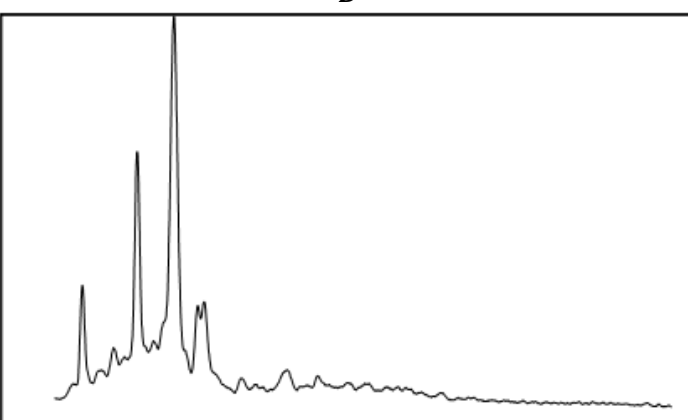

F

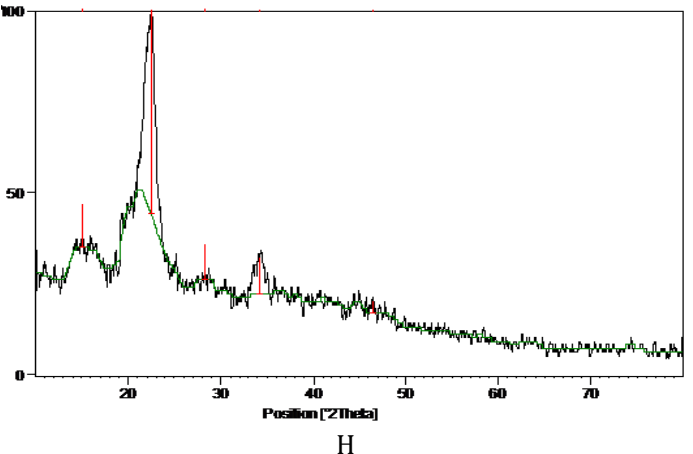

Fig. 4: XRD diffractograms: (A) Febuxostat pure drug (B) ESS4 (C) Poloxamer-188, (D) CCS (E) F4 (F) FE5 (G) FT2 (H) FT5, ESS4-Entada scandens seed starch extracted by $0.5 \%$ sodium hydroxide; CCS-Croscarmellose sodium; F4-Febuxostat and poloxamer-188 solid dispersion in 1:3 ratio; FE5-F4 solid dispersion with 12.5\% w/w of ESS4; FT2-Febuxostat FDT with 12.5\% w/w of ESS4; FT5-Febuxostat FDT with $12.5 \% \mathrm{w} / \mathrm{w}$ of CCS

Table 12: Post compression parameters of FT2 and FT5 under accelerated stability conditions

\begin{tabular}{|c|c|c|c|c|c|c|}
\hline Formulation & Storage condition & $\begin{array}{l}\text { Hardness } \\
\left(\mathrm{kg} / \mathrm{cm}^{2}\right)\end{array}$ & $\begin{array}{l}\text { Friability } \\
\text { (\% loss) }\end{array}$ & Dispersion test & Wetting time (sec) & $\begin{array}{l}\text { Drug content (mg/tablet) } \\
\text { mean } \pm S E M\end{array}$ \\
\hline \multirow{3}{*}{ FT2 } & Before Storage & $3.0 \pm 1.03$ & 0.2 & Passed & 60 & $40.22 \pm 1.56$ \\
\hline & $25 \pm 2{ }^{\circ} \mathrm{C}, 60 \pm 5 \% \mathrm{RH}$ & $3.0 \pm 1.12$ & 0.3 & Passed & 62 & $40.10 \pm 1.24$ \\
\hline & $40 \pm 2{ }^{\circ} \mathrm{C}, 75 \pm 5 \% \mathrm{RH}$ & $3.1 \pm 1.01$ & 0.2 & Passed & 62 & $40.19 \pm 1.77$ \\
\hline \multirow[t]{3}{*}{ FT5 } & Before Storage & $3.0 \pm 1.11$ & 0.2 & Passed & 64 & $40.32 \pm 1.73$ \\
\hline & $25 \pm 2{ }^{\circ} \mathrm{C}, 60 \pm 5 \% \mathrm{RH}$ & $3.1 \pm 1.54$ & 0.3 & Passed & 66 & $40.05 \pm 0.98$ \\
\hline & $40 \pm 2{ }^{\circ} \mathrm{C}, 75 \pm 5 \% \mathrm{RH}$ & $3.0 \pm 1.16$ & 0.3 & Passed & 65 & $40.21 \pm 1.91$ \\
\hline
\end{tabular}

$\mathrm{n}=3$; SEM is the standard error of the mean 


\section{CONCLUSION}

The current study shows that the proportion of starch as super disintegrant has greatly influenced the dissolution parameters of various formulations. Similar dissolution profiles were observed for formulations, FT2 containing $12.5 \% \mathrm{w} / \mathrm{w}$ of ESS4 and FT5 containing $12.5 \% \mathrm{w} / \mathrm{w}$ of CCS as super disintegrants. The super disintegrant effect of these starches might be due to the rapid uptake of water, followed by swelling that leads to an increase in hydrostatic pressure of tablet that ultimately disintegrates tablets faster. The optimized formulations showed no drug-excipient interactions when subjected to FTIR and DSC analysis. Similarly, crystallinity was observed using XRD studies. The formulations FT2 and FT5 were also found to be stable even when subjected to accelerated stability studies.

Based on the above studies, it was concluded that Febuxostat fast dissolving tablets prepared by Entada scandens seed starch extracted from $0.5 \%$ sodium hydroxide showed rapid drug release.

\section{ACKNOWLEDGMENT}

The authors are thankful to the management of Chebrolu Hanumaiah Institute of Pharmaceutical Sciences for their sheer support throughout the work. The authors also express their thanks to M/s. Mylan Laboratories Ltd., (Hyderabad, India) for their generous gift sample of Febuxostat and Dr. D. Hari Narayana, Nishka Labs, Hyderabad for their extensive support in conducting DSC, SEM and XRD studies. The authors are also thankful to Acharya Nagarjuna University, Guntur.

\section{AUTHORS CONTRIBUTIONS}

Mr. Sandeep doppalapudi the guarantor of this study has designed, carried out the experiment, analyzed the results and contributed in preparation and revision of the manuscript. Dr. Vidyadhara Suryadevara has designed, supervised the experimental process and reviewed the manuscript. Mr. Chirudeep Jujala has contributed in carrying out the experiment and preparation of manuscript.

\section{CONFLICTS OF INTERESTS}

The authors declare no conflicts of interest

\section{REFERENCES}

1. Sanjaymitra PVSS, Ganesh GNK. Dissolution and solubility enhancement strategies: current and novel prospective. J Crit Rev 2018;5:1-10.

2. Saharan VA, Kukkar V, Kataria M, Gera M, Chowdhury PK. Dissolution enhancement of drugs, part i: technologies and effect of carriers. Int J Health Res 2009;2:107-24.

3. Dhirendra K, Lewis S, Udupa N, Atin K. Solid dispersion: a review. Pak J Pharm Sci 2009;22:234-46.

4. Sreenivas SA, Gadad AP, Patil MB. Formulation and evaluation of Ondansetron hydrochloride directly compressed mouth dissolving tablets. Indian Drugs 2006;43:35-7.

5. Thomus R. Fast dissolving tablets: an overview. Eur J Pharm Sci 2007;32:58-68.

6. Bhowmik D, Chiranjib B, Yadav J, Chandira RM, Sampath KP. Emerging trends of disintegrants used in the formulation of solid dosage form. Schol Res Lib 2010;2:495-504.

7. Krishna MC, Sirish V. Formulation, development and evaluation of fast disintegrating tablets of cinitapride hydrogen tartrate by using direct compression technique. Int J Curr Pharm Res 2017;9:98-103.

8. Santosh KR, Ankita G. Design, optimization and evaluation of Piroxicam fast dissolving tablets employing starch tartrate-a new super disintegrant. Int J Appl Pharm 2019;11:89-97.

9. Sunada H, Bi Y. Preparation, evaluation and optimization of rapidly disintegrating tablets. Powder Technol 2002;122:18898.

10. Dey SK, Rahman M, Ahmed A, Khatun A, Siraj A. Phytochemical screening and pharmacological activities of entada scandens seeds. Int J Appl Res Nat Prod 2013;6:34-9.

11. Love BL, Barrons R, Veverka A, Snider KM. Urate-lowering therapy for gout: focus on febuxostat. Pharmacotherapy 2010;30:594-608.

12. Fateatun N, Jiaur RM, Sultan MM, Sorifa A, Aminul IT, Ahmed M. Physicochemical properties of flour and extraction of starch from jack fruit seed. Int I Nutr Food Sci 2014;3:347-54.

13. Menaka T, Nagaraja G, Yogesh DB, Sunil Kumar US, Prakash L. Physicochemical properties of flour and isolated starch from jackfruit seeds (Artocarpus Heterophyllus). Res J Pharm Sci 2011;1:14-8.

14. Sharda S, Bishambar S, Kirtika M, Monalisha N, Neha K, Shalini M. Solid dispersions: A tool for improving the solubility and dissolution of metronidazole. Int J Drug Delivery 2013;5:94-8.

15. Appa RB, Shivalingam M, Kishore RYV, Somesekhara R, Rajesh $\mathrm{K}$, Sunitha N. Formulation and evaluation of aceclofenac solid dispersions for dissolution rate enhancement. Int J Pharm Sci Drug Res 2010;2:146-50.

16. Okunlola A, Odeku OA. Comparative evaluation of starches obtained from Dioscorea species as intragranular tablet disintegrants. J Drug Delivery Sci Technol 2008;18:445-7.

17. Shukla D, Subhashis C, Sanjay S, Brahmeshwar M. Mouth dissolving tablets II: an overview of evaluation techniques. Pharm Sci 2009;77:327-41.

18. Dharna A, Neelam S, Sukhbir S, Sandeep A. Solid dispersions: a review on drug delivery system and solubility enhancement. Int J Pharm Sci Res 2013;4:2094-105.

19. Sangeeta $M, A b h i s e k$ P. Dissolution enhancement of seroquel by solid dispersion techniques. Asian J Pharm Clin Res 2016;9:284-7.

20. Shashikumar Y, Veena M, Srinivas M. Solid dispersion technique to enhance the solubility and dissolution rate of aripiprazole by fusion method. Int J Pharm Pharm Sci 2016;8:187-92

21. Biraju P, Dhaval P, Ramesh P, Chirag P, Tejas S, Sanja SD. Development and in vitro evaluation of fast dissolving tablets of glipizide. Int J Pharm Pharm Sci 2009;1:15-8.

22. Prasanna LA, Anand KM, Vamsi KM, Annie VK, Ashwini G. Formulation and development of irbesartan (Poorly Water Soluble Drug) immediate-release tablets. Int Res J Pharm 2012;3:34-7.

23. Roy CPA, Bhattacharyya AK, Chattopadhyay P. Study on functional properties of raw and blended Jackfruit seed flour (a non-conventional source) for food application. Indian J Nat Prod Resour 2012;3:56-9.

24. Vidyadhara S, Sasidhar RL, Lakshmi HD, Vijetha P, Vijetha K. Studies on jack fruit seed starch as a novel natural super disintegrant for the design and evaluation of Irbesartan fastdissolving tablets. Integr Med Res 2017;6:280-91. 